\title{
Level of Knowledge and Practice of Mothers on Minimum Dietary Diversity Practices and Associated Factors for 6-23-Month-Old Children in Adea Woreda, Oromia, Ethiopia
}

\author{
Andualem Agize, ${ }^{1}$ Dube Jara, ${ }^{2}$ and Getiye Dejenu ${ }^{2}$ \\ ${ }^{1}$ College of Medicine and Health Science, Debre Markos University, Debre Markos, Ethiopia \\ ${ }^{2}$ Department of Public Health, College of Medicine and Health Science, Debre Markos University, Debre Markos, Ethiopia \\ Correspondence should be addressed to Dube Jara; jaradube@yahoo.com
}

Received 19 June 2016; Revised 9 January 2017; Accepted 9 March 2017; Published 12 April 2017

Academic Editor: Louise Bennett

Copyright ( $) 2017$ Andualem Agize et al. This is an open access article distributed under the Creative Commons Attribution License, which permits unrestricted use, distribution, and reproduction in any medium, provided the original work is properly cited.

Background. Globally, undernutrition is responsible for at least $35 \%$ of deaths in children less than 5 years of age and estimated $6 \%$ of under-five deaths can be prevented by ensuring optimal complementary feeding especially the dietary diversity and meal frequency. In Ethiopia, 5\% of children were fed according to minimum standards with respect to food diversity. Objective. To assess the level of knowledge and practice of mothers on dietary diversity practices and associated factors for children 6-23 months in Adea woreda. Methods. Community-based cross-sectional study was conducted. A sample of 730 mothers who have children in the age group of 6-23 months were selected using systematic sampling. Logistic regression model was fitted in order to identify factors associated with knowledge and practice of dietary diversity practice. Result. Of the total 700, 357 (51\%) were knowledgeable on dietary diversity but $112(16 \%)$ practiced appropriate dietary diversity practice for their 6-23-month-old children. Husbands' education (AOR = $2.79,95 \% \mathrm{CI}=(1.55,5.00))$, mothers' age, and marital status were significantly associated with knowledge of mothers. Mothers' age, husbands' education, marital status, and knowledge of mothers were significantly associated with mothers' dietary diversity for 6-23-month-old children. Conclusion. This study showed that approximately half of the mothers have good knowledge on minimum dietary diversity for children 6-23 months old and very low proportion of children 6-23 months old received diversified meal according to Infant and Young Child Feeding indicators. It was identified that different factors are responsible for this discrepancy.

\section{Introduction}

The infant young child feeding model of World Health Organization (WHO) recommends introducing complementary food for infants starting at the sixth month. Breast milk has to be complemented by other foods to fill the nutrient demand of the child [1]. These complementary foods are needed to fill the calorie, protein, and micronutrient gap between the total nutritional need of the child and the amount provided by breast milk [2]. Appropriate complementary food has to be diversified and prepared from different food groups in a solid or semisolid form and needs to be initiated timely from the sixth month of the child's age by improving the quality of foods consumed as the child gets older [3].
Dietary diversity is defined as the number of the individual food items or groups consumed over a given period of time [3]. It can be measured at a household or an individual level through the use of questionnaire. More often, it is measured by counting the number of food groups [4]. Feeding practice during infancy is critical for growth, development, and health of the child and of importance for the early prevention of chronic degenerative disease [5]. Inappropriate complementary feeding increases the risk of undernutrition, illness, and mortality in infants and children [6].

Globally, undernutrition is responsible, directly or indirectly, for at least $35 \%$ of deaths in children less than five years of age. Undernutrition is also a major cause of disability preventing children who survive from reaching their full 
development potential. An estimated $32 \%$ or 186 million children below five years of age in developing countries are stunted and about $10 \%$ or 55 million are wasted [7].

An estimated $6 \%$ of under-five deaths can be prevented by ensuring optimal complementary feeding among which dietary diversity and meal frequency are the most important ones, significantly contributing to the realization of Millennium Development Goal 4 [8].

The lack of dietary diversity is a particularly severe problem among poor populations of developing countries because their diets are predominantly based on starchy staples and often include little or no animal products and few fresh fruits and vegetables. These plant-based diets tend to be low in a number of micronutrients, and the micronutrients they contain are often in a form that is not easily absorbed. Other aspects of dietary quality problems such as high intakes of fat, salt, and refined sugar in developed countries is becoming a concern for developing countries $[9,10]$.

Household level factors such as poor and middle household's socioeconomic status and lack of parental joint decision-making strategy on the treatment of the sick child and paternal education determine the nutritional status of the children. The lack of maternal access to health facilities and having a narrow birth interval and less dietary consumption from major food items were significantly associated with acute child undernutrition among the individual level factors [11].

Child dietary diversity practice was also associated with maternal dietary diversity practice. In the countries where maternal dietary diversity is high, the child dietary diversity practice is also high. In the countries where maternal dietary diversity is low, the child dietary diversity practice is also too low. In addition, the maternal power to control finance (earning money and buying food) was a key challenge to practice dietary diversity [12]. The case was not different in Ethiopia, particularly in Oromia region.

Therefore, the ultimate aim of this study will be to assess the level of knowledge and practice of mothers on dietary diversity practices and associated factors for 6-24-month-old children in Adea woreda, East Shoa Zone, Oromia, Ethiopia. The finding of this study will help policymakers and planners to set their target with feasible interventions in the study area as well as Ethiopia as a whole. It also reports on the existing gap for organizations and health workers working in the area, how to solve the problem, and how to design mechanisms for the next planning by providing information about children knowledge and practice of dietary diversity. The findings will also help zonal health department and regional health bureau to focus on identified problems in their future plan.

\section{Methods and Materials}

2.1. Study Setting and Period. The study was conducted from September 2014 to October 2014 in the Adea District, which is situated $45 \mathrm{~km}$ south of Addis Ababa and $50 \mathrm{KM}$ from zonal capital Adama town. The Adea District comprises 23 kebeles with a total population of about 121,720 . Over $90 \%$ of the district's population consists of subsistence farmers, depending heavily on rains for their agriculture. Maize, millet, cassava, and beans are the main crops cultivated in the area. There are five government-owned health centers and 23 health posts in charge of the whole population of the district. At kebele level, health posts are instituted with a health extension worker (HEW) (source: Adea woreda Health Office, 2013).

2.2. Study Design and Population. Community-based crosssectional study was conducted. The source population was mothers who have children in age group of 6-23 months who are living in Adea woreda. The study population was mothers who have children in the age range of 6-23 months who were selected to participate in the study. The mothers who were permanent resident of the study area were included in the study. Those mothers who are chronically ill were excluded from the study.

2.3. Sample Size and Sampling. The required sample size was determined using single population proportion formula. In this regard, $8.5 \%$ proportion of diversified dietary practice taken from previous studies conducted in northwest Ethiopia Enemay district, with a 3\% margin of error and a 5\% level of significance (two-sided), were assumed. Based on the above assumptions, considering a design effect of 2 since complex sampling (multistage) was used and adding $10 \%$ nonresponse rate, the total sample size was 730 . Multistage sampling technique was used to selected the study subjects. Eight kebeles of the woreda were selected using simple random sampling from 23 kebeles. The calculated sample size was allocated to each selected kebele proportional to the size of the population and the study participants were selected using systematic random sampling through house number of each household of kebele.

2.4. Variables and Measurements. The dependent variable of the study was the knowledge and practice on minimum dietary diversity provision whereas the independent variables were sociodemographic variables (age, educational level, religion, marital status, ethnicity, family size, birth order, and season), socioeconomic characteristics (income, occupation, household economy control, livestock possession, exposure to information, etc.).

Good Dietary Diversity. Children 6-23 months of age who received foods from four or more food groups of the seven food groups [(1) grain, root, and tubers, (2) legumes and nuts, (3) dairy products, (4) flesh food, (5) egg, (6) vitamin A-rich fruit and vegetables, and (7) other fruit and vegetables] are used to have minimum dietary diversity [13].

Knowledge. Those who score above the average (mean) in knowledge assessing questions were categorized as knowledgeable and those who score below the average (mean) were categorized as not knowledgeable.

Practice. Those who fed their child with 4 or more food groups were categorized as practicing good dietary diversity (minimum acceptable diet) and below 4 groups were categorized as not practicing good dietary diversity. 
Kebele. The smallest administrative unit of the country is called kebele.

2.5. Data Collection Methods. A structured questionnaire was developed based on previous studies and WHO recommendations to assess the dietary diversity by taking the local situation into consideration. The questionnaire was prepared in English and it was translated to Afan Oromo language (local language). Data were collected by trained data collectors and supervisors. The principal investigator organized a two-day training to introduce the objectives of the study and data collection process. The questionnaire was pretested out of the study area. The interview was administered in Afan Oromo language (local language). The data quality was assured by performing strong supervision by immediate supervisors. The supervisors also checked the completeness and consistency of questionnaires on daily basis. The principal investigator had also rechecked the completed questionnaires to maintain quality and has supervised five percent of the surveyed households to confirm whether the houses were interviewed in the intended way.

2.6. Data Processing and Analysis. The collected data were entered using EPI INFO statistical packages version 6.02. Then, they were exported to SPSS version 20 for analysis. The descriptive analysis was conducted to describe number and percentage distribution of variables. Binary logistic regression model was fitted to identify the association between outcome variable and explanatory variables. The crude and adjusted odds ratio together with its corresponding 95\% confidence intervals was computed. A $P$ value $<0.05$ was considered to declare a result as statistically significant in this study.

2.7. Ethical Clearance. The ethical clearance was obtained from Debre Markos University College of Medicine and Health Sciences. A necessary permission was also obtained from Oromia regional health bureau and Adea woreda health office and local administrations. An informed verbal consent was obtained from the study participants and the privacy of the participants and confidentiality of the information were assured. Mothers with no and low awareness on dietary diversity for 6-23-month-old children were informed on the recommended practices and were referred to health facilities working nearby.

\section{Results}

3.1. Sociodemographic and Socioeconomic Characteristics of Respondents. Of a total of 730 sampled mothers, 700 were interviewed with an overall response rate of $95.9 \%$. Four hundred thirty-seven (62.4\%) of the respondents belonged to the age group of 25-34 years and five hundred fifteen (73.6\%) of the respondents were Oromo and 176 (25.1\%) were Amhara in ethnic group. The majority, 409 (58.4\%), had children in the age group of 12 to 18 months. Four hundred twentyfour $(60.6 \%)$ of the respondents attended their education to the primary level. Six hundred fifty-eight (94\%) of the mothers were married and living with their husbands and $468(66.6 \%)$ of the interviewed mothers' husbands attended
TABLE 1: Sociodemographic and socioeconomic characteristics of respondents, Adea woreda, East Shoa Zone, Oromia region, 2014.

\begin{tabular}{|c|c|c|}
\hline Variables & Number & Percent (\%) \\
\hline \multicolumn{3}{|l|}{ Mother's age } \\
\hline $15-24$ years & 176 & 25.1 \\
\hline $35-44$ years & 437 & 62.4 \\
\hline $25-34$ years & 87 & 12.4 \\
\hline \multicolumn{3}{|l|}{ Child's age in months } \\
\hline 6 to 11 months & 203 & 29.0 \\
\hline 12 to 18 months & 409 & 58.4 \\
\hline 19-23 months & 88 & 12.6 \\
\hline \multicolumn{3}{|l|}{ Mother's educational status } \\
\hline No schooling & 220 & 31.4 \\
\hline Primary & 424 & 60.6 \\
\hline Secondary and above & 56 & 8 \\
\hline \multicolumn{3}{|c|}{ Husband's educational status } \\
\hline No schooling & 95 & 13.6 \\
\hline Primary & 468 & 66.9 \\
\hline Secondary and above & 137 & 19.5 \\
\hline \multicolumn{3}{|l|}{ Religion } \\
\hline Orthodox & 489 & 69.9 \\
\hline Muslim & 72 & 10.2 \\
\hline Protestant & 139 & 19.9 \\
\hline \multicolumn{3}{|l|}{ Marital status } \\
\hline Single & 19 & 2.7 \\
\hline Married & 658 & 94.0 \\
\hline Divorced & 23 & 3.3 \\
\hline \multicolumn{3}{|l|}{ Family size } \\
\hline Below five & 242 & 34.6 \\
\hline Five and above & 458 & 65.4 \\
\hline \multicolumn{3}{|c|}{$\begin{array}{l}\text { Number of 6-23-month-old children in } \\
\text { the HH }\end{array}$} \\
\hline One & 666 & 96.0 \\
\hline Two and above & 34 & 4.9 \\
\hline \multicolumn{3}{|l|}{ Monthly income } \\
\hline 501 to 1000 birr & 391 & 55.9 \\
\hline 1001 to 3000 birr & 309 & 44.1 \\
\hline \multicolumn{3}{|l|}{ HH economy controlled by } \\
\hline Husband only & 645 & 92.1 \\
\hline Housewife only & 30 & 4.3 \\
\hline Both husband and wife & 25 & 3.6 \\
\hline
\end{tabular}

HH: household.

their education to the primary level. Four hundred eightynine $(69.6 \%)$ of the responding mothers were followers of orthodox Christian. Four hundred fifty-eight (65.4\%) had family size of five and more members and 391 (55.9\%) of the mothers had a monthly income of 501 to 1000 ETB. The household economy of six hundred forty-five (92\%) mothers was controlled by husbands only (Table 1). 
TABLE 2: Knowledge level of the interviewed mothers on minimum dietary diversity in Adea woreda, East Shoa Zone, Oromia region, November 2014.

\begin{tabular}{lcc}
\hline Knowledge responses & Number & Percent \% \\
\hline $\begin{array}{l}\text { Age when complementary feeding was } \\
\text { initiated }\end{array}$ & & \\
$\quad$ At the sixth month & 670 & 95.7 \\
$\quad$ Other & 30 & 4.3 \\
Importance of giving additional food & 589 & 84.1 \\
$\quad$ Breast milk alone is not sufficient & 111 & 15.9 \\
$\quad$ Other & & \\
Pictures of porridge the mother chose & 61 & 8.7 \\
$\quad$ Show thick porridge & 639 & 91.3 \\
$\quad$ Show watery porridge & & \\
Type of food added to porridge & 253 & 36.1 \\
$\quad$ Three and above groups & 447 & 63.9 \\
$\quad$ Less than three groups & & \\
$\begin{array}{l}\text { Recommendation on bottle feeding with } \\
\text { nipple }\end{array}$ & & \\
$\quad$ No & 127 & 18.1 \\
Yes & 573 & 81.9 \\
Knowledge status of mother & & \\
Not knowledgeable & 343 & 49 \\
Knowledgeable & & \\
\hline
\end{tabular}

3.2. Knowledge of Mothers. The knowledge status of the mothers was assessed based on their self-responses. As a result, 357 (51\%) respondents were knowledgeable on minimum dietary diversity practice. Six hundred seventy $(95.7 \%)$ were knowledgeable on when to start complementary feeding. Four hundred one (57.3\%) respondents breastfed their children for $12-23$ months and 589 (84.1\%) of the respondents were knowledgeable on why it is important to start giving their children food in addition to breast milk. In addition, $61(8.7 \%)$ of respondents demonstrated the recommended thick porridge and $252(36 \%)$ mentioned three and above food groups used to enrich a porridge. Regarding feeding methods, $572(81.7 \%)$ participants reported feeding the child with a bottle as a recommended feeding option (Table 2).

3.3. Practice of Mothers in Provision of Diversified Diet. The majority, 663 (94.7\%), of the respondents provided injera, bread, rice made of teff, oat, maize, barley, or wheat. Fourteen (2\%) of the respondents provided juice or juice drinks and nine $(1.35 \%)$ respondents provided organ meat like liver, kidney, and heart and sixty-eight (9.7\%) respondents provided meat of ox, hen, sheep, or calf one day before the interview. Fourteen $(2 \%)$ of respondents provided ripe mango or papaya and $23(3.3 \%)$ of respondents provided pumpkin, carrot, squashed potato, or sweet potato that are yellow in color.

Generally, out of the seven hundred mothers interviewed, one hundred twelve (16\%) responded that they have provided complementary food prepared of four and above food groups which is considered as good dietary practice (Table 3 ).
TABLE 3: Level of practice of the interviewed mothers on minimum dietary diversity for 6-23-month-old children, Adea woreda, East Shoa Zone, Oromia region, 2014.

\begin{tabular}{lcc}
\hline Practice assessing questions responses & Number & Percent \% \\
\hline $\begin{array}{l}\text { Child drank juice or juice drinks yesterday } \\
\text { during day or night }\end{array}$ & & \\
No & 686 & 98 \\
Yes & 14 & 2
\end{tabular}

Child ate injera, bread, rice made from teff, oat, maize, barley, wheat

$\begin{array}{lcc}\text { No } & 37 & 5.3 \\ \text { Yes } & 663 & 94.7\end{array}$

Child ate tinned, powdered, fresh animal milk or yoghurt yesterday

$\begin{array}{lll}\text { No } & 393 & 56.1 \\ \text { Yes } & 307 & 43.9\end{array}$

Child ate pumpkin, carrot, squash, or sweet potato that are yellow

$\begin{array}{lcc}\text { No } & 677 & 96.7 \\ \text { Yes } & 23 & 3.3\end{array}$

Child ate ripe mango or papaya yesterday during day or night

$\begin{array}{lcc}\text { No } & 686 & 98 \\ \text { Yes } & 14 & 2\end{array}$

Child ate any dark green leafy vegetables like kale, spinach

$\begin{array}{lll}\text { No } & 541 & 77.3 \\ \text { Yes } & 159 & 22.7\end{array}$

Child ate any other fruit or vegetables yesterday during day or night

$\begin{array}{lll}\text { No } & 558 & 79.7 \\ \text { Yes } & 142 & 20.3\end{array}$

Child ate meat of ox, pig, hen, sheep, or calf yesterday during day or night

$\begin{array}{ccc}\text { No } & 632 & 90.3 \\ \text { Yes } & 68 & 9.7\end{array}$

Child ate rgg yesterday during day or night

$\begin{array}{lll}\text { No } & 358 & 51.1 \\ \text { Yes } & 342 & 48.9\end{array}$

Child ate any foods made from beans, peas, lentils, or nuts yesterday

$\begin{array}{lll}\text { No } & 126 & 18 \\ \text { Yes } & 574 & 82\end{array}$

Dietary diversity practice status of mother

\begin{tabular}{lcc} 
Not good & 588 & 84 \\
Good & 112 & 16 \\
\hline
\end{tabular}

3.4. Factors associated with Knowledge of Mothers on Dietary Diversity Practice for 6-23-Month-Old Children. Maternal age, husbands' education, marital status, and source of health information had a statistically significant association with 
TABLE 4: Factors associated with knowledge of mothers towards dietary diversity in Adea district, Ethiopia, 2014.

\begin{tabular}{|c|c|c|c|c|c|}
\hline \multirow{2}{*}{ Variable } & \multicolumn{2}{|c|}{ Knowledge status } & \multirow{2}{*}{$\begin{array}{l}\text { Crude odds ratio } \\
(95 \% \mathrm{CI})\end{array}$} & \multirow{2}{*}{$\begin{array}{l}\text { Adjusted OR } \\
(95 \% \mathrm{CI})\end{array}$} & \multirow{2}{*}{$P$ value adjusted } \\
\hline & Knowledgeable & Not knowledgeable & & & \\
\hline \multicolumn{6}{|l|}{ Mother's age in year } \\
\hline $15-24$ years & 85 & 91 & 1 & & \\
\hline 25-34 years & 243 & 194 & $1.34(0.94,1.90)$ & $1.27(0.86,1.87)$ & 0.233 \\
\hline $35-44$ years & 29 & 58 & $0.54(0.31,0.91)$ & $0.46(0.26,0.83)^{*}$ & 0.010 \\
\hline \multicolumn{6}{|l|}{ Husband's education status } \\
\hline Cannot read and write & 38 & 57 & 1 & & \\
\hline Primary & 226 & 242 & $1.40(0.89,2.19)$ & $1.23(0.76,1.98)$ & 0.404 \\
\hline Secondary and above & 93 & 44 & $3.17(1.84,5.47)$ & $2.79(1.55,5.00)^{*}$ & 0.001 \\
\hline \multicolumn{6}{|l|}{ Marital status } \\
\hline Single & 15 & 4 & 1 & & \\
\hline Married & 328 & 330 & $0.27(0.09,0.81)$ & $0.17(0.05,0.56)^{*}$ & 0.002 \\
\hline Divorced & 14 & 9 & $0.42(0.10,1.66)$ & $0.35(0.08,1.52)$ & 0.161 \\
\hline \multicolumn{6}{|l|}{ Season in which all food is available } \\
\hline Summer & 77 & 97 & 1 & & \\
\hline Winter & 280 & 246 & $1.43(1.02,2.02)$ & $1.46(1.01,2.12)^{*}$ & 0.047 \\
\hline \multicolumn{6}{|l|}{ Household income } \\
\hline 501-1000 birr & 170 & 221 & 1 & & \\
\hline $1001-3000$ birr & 187 & 122 & $1.99(1.47,2.70)$ & $1.79(1.28,2.51)^{*}$ & 0.001 \\
\hline \multicolumn{6}{|l|}{ Source of health information } \\
\hline From health post & 85 & 101 & 1 & & \\
\hline From Health center & 15 & 40 & $0.47(0.23,0.86)$ & $0.47(0.23,0.93)^{*}$ & 0.030 \\
\hline HP \& health development army & 167 & 161 & $1.23(0.59,1.77)$ & $1.14(0.78,1.67)$ & 0.504 \\
\hline HP and media & 90 & 41 & $2.61(1.63,4.17)$ & $2.25(1.37,3.69)^{*}$ & 0.001 \\
\hline
\end{tabular}

Note. ${ }^{*}$ Statistically significant at $P$ value $<0.05$ and $95 \%$ CI. 1: reference category.

the outcome variables. Mothers whose age belongs to the age group of 35-44 years were 54\% times less likely knowledgeable as compared with mothers whose age belongs to the age group of $15-24$ years $(\mathrm{AOR}=0.46,95 \% \mathrm{CI}=(0.26$, $0.83)$ ). Those mothers whose husbands' had attended their education to the secondary and above level were 2.79 times more knowledgeable on minimum dietary diversity for 6-23month-old children as compared to those mothers whose husbands cannot read and write $(\mathrm{AOR}=2.79,95 \% \mathrm{CI}=$ $(1.55,5.00))$. Those mothers who were married and living with their husbands were $83 \%$ times less likely knowledgeable compared to single mothers $(\mathrm{AOR}=0.17,95 \% \mathrm{CI}=(0.05$, $0.56)$ ). Mothers who responded that all food groups will be accessible in their household in winter were 1.46 times more knowledgeable as compared to mothers who will have access to all food groups in summer $(\mathrm{AOR}=1.46,95 \% \mathrm{CI}=(1.01$, 2.12)). Mothers whose monthly income ranges between 1001 and 3000 Ethiopian birr were 1.79 times more knowledgeable as compared with those whose monthly income ranges between 501 and 1000 birr $(\mathrm{AOR}=1.79,95 \% \mathrm{CI}=(1.28,2.51))$.

Mothers who received health information from health centers were $53 \%$ times less knowledgeable as compared with mothers who received health information from health posts only $(\mathrm{AOR}=0.47,95 \% \mathrm{CI}=(0.23,0.93))$. And mothers who received health information from health posts and media like radio and television were 2.25 times more knowledgeable as compared with mothers who received health information from health posts only $(\mathrm{AOR}=2.25,95 \% \mathrm{CI}=(1.37,3.96))$ (Table 4).

3.5. Factors associated with Dietary Diversity Practice of Mothers of 6-23-Month-Old Children. Maternal age, husbands' education, marital status, seasonal availability of food, access to all food groups, source of health information, and knowledge of mother had a statistically significant association with outcome variable. Those mothers who belong to the age group of 25-34 years were 1.82 times more likely to practice good dietary diversity for their 6-23-month-old children as compared with those who belong to the age group of 15-24 years $(\mathrm{AOR}=1.82,95 \% \mathrm{CI}=(1.05,3.17))$. Mothers who were married and living with their husbands were $88 \%$ times less likely to practice good dietary diversity as compared with single mothers $(\mathrm{AOR}=0.22,95 \% \mathrm{CI}=(0.08,0.59))$. And those mothers who were divorced were $91 \%$ times less likely to practice good dietary diversity compared to single mothers $(\mathrm{AOR}=0.09,95 \% \mathrm{CI}=(0.02,0.53))$. Mothers' dietary diversity practice was also affected by seasonal availability of food groups to diversify meal for their 6-23-month-old children. Mothers who can have access to all food groups in winter were 1.78 times more likely to practice good dietary diversity as 
TABLE 5: Factors associated with mothers' dietary diversity practice in Adea district, Ethiopia, 2014.

\begin{tabular}{|c|c|c|c|c|c|}
\hline \multirow{2}{*}{ Variable } & \multicolumn{2}{|c|}{ DD practice } & \multirow{2}{*}{$\begin{array}{l}\text { Crude odds ratio } \\
(95 \% \mathrm{CI})\end{array}$} & \multirow{2}{*}{$\begin{array}{l}\text { Adjusted OR } \\
(95 \% \mathrm{CI})\end{array}$} & \multirow{2}{*}{$\begin{array}{l}P \text { value } \\
\text { adjusted }\end{array}$} \\
\hline & Good & Not good & & & \\
\hline \multicolumn{6}{|l|}{ Mother's age in year } \\
\hline $15-24$ years & 21 & 155 & 1 & & \\
\hline $25-34$ years & 81 & 356 & $1.68(1.00,2.81)$ & $1.82(1.05,3.17)^{*}$ & 0.026 \\
\hline $35-44$ years & 10 & 77 & $0.96(0.43,2.14)$ & $1.29(0.55,3.03)$ & 0.553 \\
\hline \multicolumn{6}{|l|}{ Marital status } \\
\hline Single & 9 & 10 & 1 & & \\
\hline Married & 101 & 557 & $0.20(0.80,0.51)$ & $0.22(0.08,0.59)^{*}$ & 0.003 \\
\hline Divorced & 2 & 21 & $0.11(0.02,0.58)$ & $0.09(0.02,0.53)^{*}$ & 0.008 \\
\hline \multicolumn{6}{|l|}{ Season in which all food is available } \\
\hline Summer & 19 & 155 & 1 & & \\
\hline Winter & 93 & 433 & $1.75(1.04,2.97)$ & $1.78(1.01,3.15)^{*}$ & 0.046 \\
\hline \multicolumn{6}{|l|}{ Source of health information } \\
\hline From health post & 41 & 145 & 1 & & \\
\hline From health center & 4 & 51 & $0.28(0.10,0.81)$ & $0.36(0.12,1.10)$ & 0.073 \\
\hline HP \& health development army & 42 & 286 & $0.52(0.32,0.84)$ & $0.48(0.29,0.79)^{*}$ & 0.004 \\
\hline $\mathrm{HP}$ and media & 25 & 106 & $0.83(0.48,1.46)$ & $0.68(0.37,1.22)$ & 0.192 \\
\hline \multicolumn{6}{|l|}{ Knowledge status } \\
\hline Knowledgeable & 85 & 272 & 1 & & \\
\hline Not knowledgeable & 27 & 316 & $0.27(0.17,0.43)$ & $0.30(0.18,0.48)^{*}$ & 0.000 \\
\hline
\end{tabular}

Note. ${ }^{*}$ Statistically significant at $P$ value $<0.05$ and $95 \%$ CI. 1: reference category.

compared with those mothers who can have access to all food groups in summer $(\mathrm{AOR}=1.78,95 \% \mathrm{CI}=(1.01,3.15))$.

This study revealed that source of health information had also a significant effect on dietary diversity practice for 6-23-month-old children. Mothers who received health information from health posts and health development army (HDA) were $52 \%$ times less likely to practice good dietary diversity for their children as compared with those mothers who received health information from health posts only $(\mathrm{AOR}=0.48,95 \% \mathrm{CI}=(0.29,0.79))$.

The knowledge of the mother was also computed as an explanatory variable for dietary diversity practice. Accordingly, mothers who were not knowledgeable on dietary diversity were $70 \%$ times less likely to practice good dietary diversity for 6-23-month-old children as compared with their counterparts $(\mathrm{AOR}=0.30,95 \% \mathrm{CI}=(0.18,0.48))$ (Table 5$)$.

\section{Discussion}

The feeding practice during infancy is critical for growth, development, and health of child and of importance for the early prevention of chronic degenerative disease [5]. Inappropriate complementary feeding increases the risk of undernutrition, illness, and mortality in infants and children [6]. Complementary foods are additional foods which are provided in addition to breast milk in order to fill the energy gap demanded by the children for proper growth and development. Therefore, the objective of this study is to assess the level of knowledge and practice of mothers on dietary diversity practices and associated factors for 6-23-month-old children in Adea woreda, East Shoa Zone, Oromia.

The finding of this study revealed that $51 \%$ of the respondents were knowledgeable on dietary diversity. About 95.7\% of the respondents reported that a child has to start complementary food at the sixth month in addition to breast milk which was similar to the findings of the study conducted in Accra, Ghana [14]. A very low proportion of the mothers were knowledgeable on the consistency of complementary food for 6-23-month-old children, that they show pictures of thick porridge. About $36.1 \%$ of the respondents had mentioned three and above food groups which can be added to complementary food to enrich porridge and were categorized as knowledgeable. This finding is consistent with the report of the Food and Nutrition Technical Assistance [15].

Husbands' education status showed statistically significant association with mothers' knowledge on dietary diversity for 6-23-month-old children. The mothers whose husbands had had secondary and above education level were more knowledgeable on dietary diversity for 6-23-month-old children. This finding is consistent with the finding of the study conducted in Bangladesh [16].

Mothers who were married and living with their husbands were more knowledgeable as compared with single and divorced mothers. This can strengthen the above suggestion that husbands can discuss the children feeding with their wives. Household monthly income was significantly associated with mothers' knowledge on minimum dietary diversity. Mothers whose household income was high were 
more knowledgeable compared to mothers whose income was low and the practice was also higher and this finding is in line with that of the study done in India [17].

In this study, most of the respondents (99\%) breastfed their children during the interview and $94.7 \%$ of respondents had provided grain-based food for their children, $48.9 \%$ have provided egg, and only $9.7 \%$ have provided flesh food like meat of ox, sheep, or hen. This finding was higher in the practice of dietary diversity when compared with the findings in Ethiopian Demographic and Health survey 2011 [18]. Though there is increment in the practice, still body building food group like flesh food consumption is very low. This might be due to knowledge gap on flesh food consumption or other sociodemographic characteristics of mothers.

This study revealed that $16 \%$ of the respondents practiced good dietary diversity (minimum dietary diversity) for 6-23month-old children. This finding is higher as compared with the findings of studies on minimum dietary diversity practices for 6-23-month-old children conducted in Enemay woreda, North West Ethiopia, which was 8.5\% (28) and with finding of Ethiopian Demographic and Health Survey 2011 which was 5\% [18]. This might be due to the different Infant and Young Child Feeding interventions in the study woreda. The finding was almost similar to that of the study conducted in India in which the minimum dietary diversity practice was $15.2 \%$ [17]. This finding is very low compared to that of the study done in Bangladesh, Sri Lanka, Nepal, and Ghana in which the minimum dietary diversity practice for 6-23-month-old children was $41.9 \%, 71 \%$, $34 \%$, and $41.8 \%$, respectively $[16,19-21]$. This might be due to the economic status of the mothers in these countries.

Mothers' age was associated with child dietary diversity practice. Mothers whose age belongs to the age group of 25-34 years practiced good dietary diversity (minimum acceptable dietary diversity) than mothers that belong to any other age groups. This could be due to the increase of dietary diversity feeding practice as the age of the mother increases and the mothers gain experience in child feeding. Seasonal availability of food group was also found to be statistically significantly associated with dietary diversity practice for 6-23-month-old children. Dietary diversity practice was higher among respondents who can have access to all food groups in winter compared to in summer. This could be due to the increased access to all food groups by selling the household surplus production.

The source of health information was found to have statistically significant association with the minimum dietary diversity practice for 6-23-month-old children. The respondents who receive health information from health posts were practicing good dietary diversity (minimum dietary diversity) for their children compared to mothers who receive health information from health centers and messages from both health posts and health development army (HDA). This might be because, in the health posts (HP), health extension workers are providing more health education and give more time to discuss nutrition with mothers and the messages are clearly communicated with no language barrier. In addition, more preventive nutrition training sessions are offered for HEW and there is less turnover of the trained health extension workers (HEW) in HP than in health centers.

There was very high difference between the knowledge of the mothers on dietary diversity (51\%) and minimum dietary diversity practice for 6-23-month-old children which was $16 \%$. This finding is similar to that of the study conducted in Accra, Ghana [22]. This indicates and strengthens those different sociodemographic factors like mothers' age, husbands' education, and source of information and economic factors like household income could affect dietary diversity significantly. As the study was conducted by interviewing mothers on the past 24-hour feeding practice for their 6-23-month-old children, there might be a recall bias and the study does not address the amount and quality of the complementary food.

\section{Conclusion}

This study has shown that approximately half of the mothers have good knowledge on minimum dietary diversity for 6-23-month-old children and that very low proportion of 6-23-month-old children receive diversified meal according to Infant and Young Child Feeding indicators. In general, minimum dietary diversity practice for 6-23-month-old children was below the Infant and Young Child Feeding recommendation. It was identified that mothers' knowledge was affected by mothers' age, husbands' education status, marital status, household income, and source of health information. Mothers' dietary diversity practice was also found to be affected by different sociodemographic and economic factors such as mother's age, marital status, and seasonal availability of all food groups and strongly associated with the source of health information. The association found between knowledge and practice outcome suggests that increasing knowledge of mothers on dietary diversity could improve dietary diversity practice of mothers for 6-23-month-old children. Based on the finding of this study, the following recommendations were forwarded to different stakeholders:

(i) Health sector needs to design a community-based nutrition focused behavioral change communication at a community level to equip and enhance community knowledge and to change knowledge into practice of proper dietary diversity for 6-23-monthold children.

(ii) Enhancing health workers' knowledge and skill in transferring nutrition-based health information for mothers at health center level could help mothers who receive health information from $\mathrm{HC}$ to practice dietary diversity properly.

(iii) Media has to strengthen social behavioral change and communication at community level to change knowledge on dietary diversity to practice. In addition, animal source food utilization has to be promoted.

(iv) Government has to urge partners working in the area of nutrition to promote mobile kitchen to promote food cooking demonstration at community level which could strengthen communities' skill in practicing dietary diversity using locally available foods. 
(v) Ministry of Women and woreda women offices needs to promote mothers education to enhance mothers' knowledge and increase level of dietary diversity practice.

(vi) In order to make all food groups at household level available throughout all the seasons, Agriculture Bureau and Office needs to promote home stead gardening and permagarden to produce vegetables and fruits at the $\mathrm{HH}$ level. This will improve access to fruits and vegetables throughout the year and improve DD of children.

(vii) Ministry of Education and Education Office have to expand education to all levels and strengthen education for all especially teaching husbands which plays a significant role in changing wives'/mothers' knowledge level.

(viii) Further study has to be conducted in the area to determine adequacy of nutrient intake and on comparison of nutrient intake and nutritional status of 6-23-month-old children.

\section{Conflicts of Interest}

The authors declare that they have no conflicts of interest.

\section{Authors' Contributions}

Andualem Agize, Dube Jara, and Getiye Dejenu participated in the proposal writing and data collection, analyzed the data, and drafted the paper. Dube Jara also prepared the manuscript for publication. All the authors revised the subsequent drafts of the paper.

\section{Acknowledgments}

The authors' deep gratitude goes to College of Medicine and Health Sciences, Debre Markos University, for the proper review and approval of this paper. The authors would also like to extend their gratitude to the participants, data collectors, and supervisors for their valuable contribution to giving good information and data collection, respectively.

\section{References}

[1] World Health Organization, Infant and Young Child Feeding: Model Chapter for Textbooks for Medical Students and Allied Health Professionals, WHO, Geneva, Switzerland, 2009.

[2] Federal Ministry of Health Ethiopia, Infant and Young Child Feeding IYCF National Guideline, Federal Ministry of Health Ethiopia, Addis Ababa, Ethiopia, 2003.

[3] "Strengthening Infant and Young Child Feeding Programming and Planning for Emergency Preparedness and Response Proceedings of an international workshop, London, UK," 25th29th June 2012, http://www.unicef.org/nutritioncluster/files/ IYCF_-_IYCF-E_workshop_report_2012.pdf.

[4] M. T. Ruel, "Is dietary diversity an indicator of food security or dietary quality? A Review of Measurement Issues and Research Needs," FCND Discussion Paper 140, Food Consumption and
Nutrition Division, International Food Policy Research Institute (IFPRI), 2002.

[5] R. E. Black, L. H. Allen, Z. A. Bhutta et al., "Maternal and child undernutrition: global and regional exposures and health consequences," The Lancet, vol. 371, no. 9608, pp. 243-260, 2008.

[6] C. Lutter, "Meeting the challenge to improve complementary feeding and strengthening action to feeding," SCN News, vol. 27, pp. 4-9, 2003.

[7] World Health Organization and Department of Health Statistics and Informatics of the Information, World Health Statistics, World Health Organization, Geneva, Switzerland, 2010, http://www.who.int/gho/publications/world_health_statistics/ EN_WHS10.

[8] R. E. Black, S. S. Morris, and J. Bryce, "Where and why are 10 million children dying every year?" Lancet, vol. 361, no. 9376, pp. 2226-2234, 2003.

[9] World Health Organization, "Preparation and use of foodbased dietary guidelines," WHO Technical Report 880, Report of a Joint FAO/ WHO Consultation. World Health Organization, Geneva, Switzerland, 1996.

[10] B. M. Popkin, "The nutrition transition in low-income countries: an emerging crisis," Nutrition Reviews, vol. 52, no. 9, pp. 285-298, 1994.

[11] G. Egata, Y. Berhane, and A. Worku, "Predictors of acute undernutrition among children aged 6 to 36 months in east rural Ethiopia: a community based nested case-control study," BMC Pediatrics, vol. 14, no. 1, article 91, 2014.

[12] M. Arimond and M. T. Ruel, "Dietary diversity is associated with child nutritional status: evidence from 11 demographic and health surveys," Journal of Nutrition, vol. 134, no. 10, pp. 25792585, 2004.

[13] World Health Organization, Indicators for Assessing Infant and Young Child Feeding Practices. Conclusions of a Consensus Meeting Held 6-8 November 2007 in Washington D.C., USA, 2007.

[14] A. D. Disha, R. Rawat, A. Subandoro, and P. Menon, "Infant and child feeding IYCF practices in Ethiopia and Zambia and their association with child nutrition," African Journal of Food, Agriculture, Nutrition and Development, vol. 12, no. 2, pp. 58965909, 2012.

[15] Working Group on Infant and Young Child Feeding Indicators, "Developing and validating simple indicators of dietary quality and energy intake of infants and young children in developing countries," Tech. Rep., Food and Nutrition Technical Assistance (FANTA) Project/Academy for Educational Development (AED), Washington, DC, USA, 2007.

[16] I. Kabir, M. Khanam, K. E. Agho, S. Mihrshahi, M. J. Dibley, and S. K. Roy, "Determinants of inappropriate complementary feeding practices in infant and young children in Bangladesh: secondary data analysis of Demographic Health Survey 2007," Maternal \& Child Nutrition, vol. 8, supplement 1, pp. 11-27, 2012.

[17] A. Patel, Y. Pusdekar, N. Badhoniya, J. Borkar, K. E. Agho, and M. J. Dibley, "Determinants of inappropriate complementary feeding practices in young children in India: secondary analysis of National Family Health Survey 2005-2006," Maternal and Child Nutrition, vol. 8, no. 1, pp. 28-44, 2012.

[18] Central Statistical Agency Ethiopia and ICF International, Ethiopian Demographic and Health Survey 2011, Central Statistical Agency, Addis Ababa, Ethiopia; ICF International, Calverton, Md, USA, 2012.

[19] U. Senarath, S. S. P. Godakandage, H. Jayawickrama, I. Siriwardena, and M. J. Dibley, "Determinants of inappropriate 
complementary feeding practices in young children in Sri Lanka: secondary data analysis of Demographic and Health Survey 2006-2007," Maternal and Child Nutrition, vol. 8, no. 1, pp. 60-77, 2012.

[20] N. Joshi, K. E. Agho, M. J. Dibley, U. Senarath, and K. Tiwari, "Determinants of inappropriate complementary feeding practices in young children in Nepal: secondary data analysis of Demographic and Health Survey 2006," Maternal and Child Nutrition, vol. 8, no. 1, pp. 45-59, 2012.

[21] S. Gyampoh, G. Otoo, and R. Aryeetey, "Maternal nutrition knowledge is associated with meeting the minimum acceptable diet among children 6-23 months, Ghana," Annals of Nutrition and Metabolism, vol. 63, supplement 1, pp. 1124-1130, 2013.

[22] S. Gyampoh, G. E. Otoo, and R. N. O. Aryeetey, "Child feeding knowledge and practices among women participating in growth monitoring and promotion in Accra, Ghana," BMC Pregnancy and Childbirth, vol. 14, no. 1, article 180, 2014. 


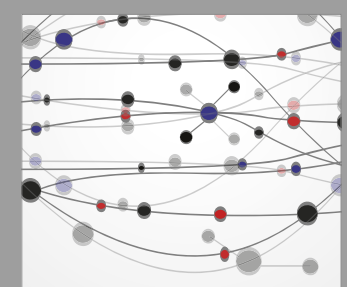

The Scientific World Journal
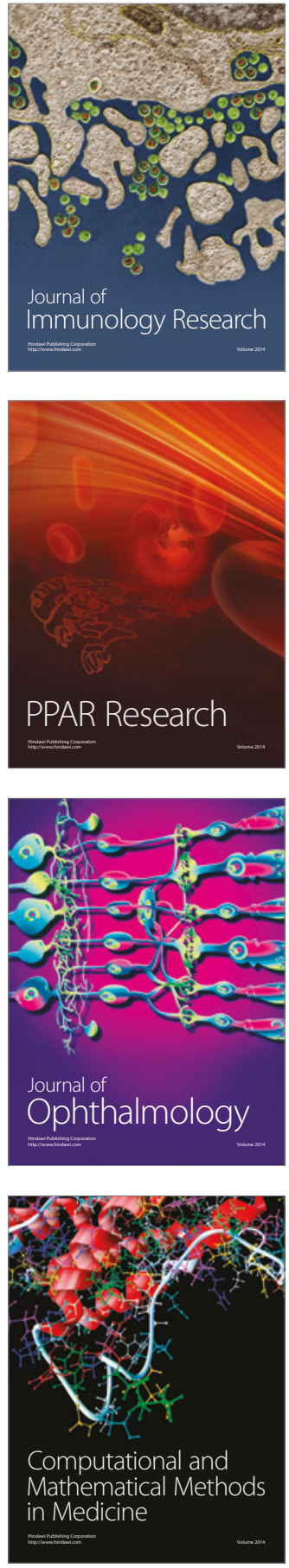

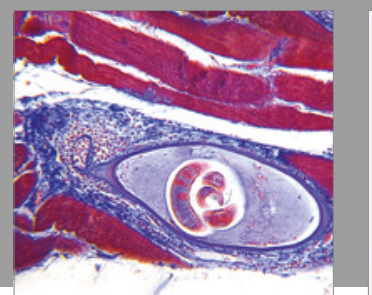

Gastroenterology Research and Practice
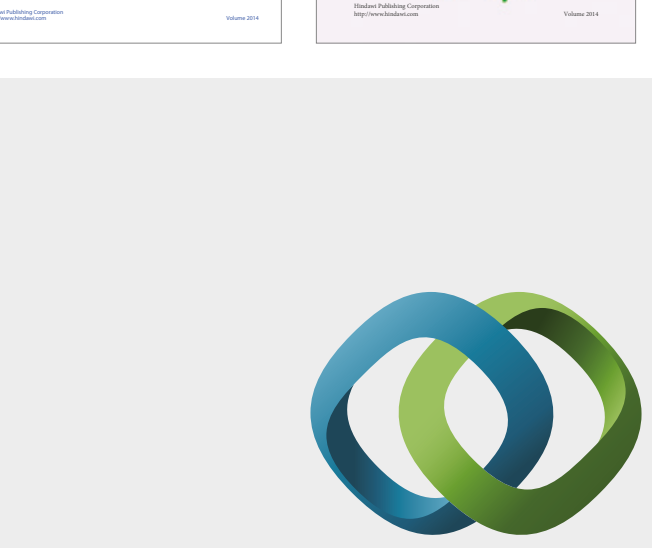

\section{Hindawi}

Submit your manuscripts at

https://www.hindawi.com
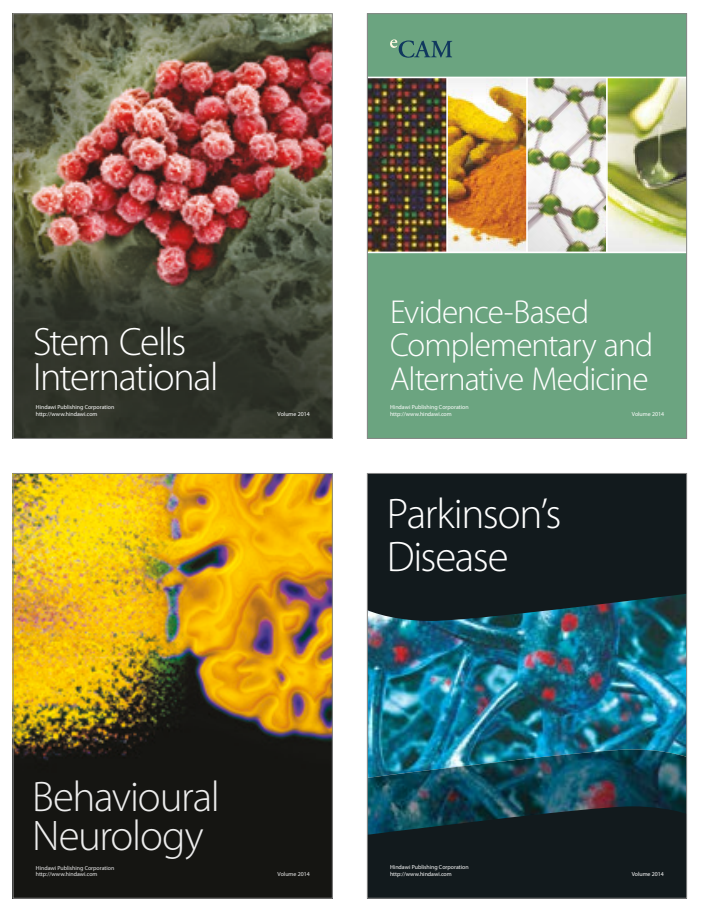
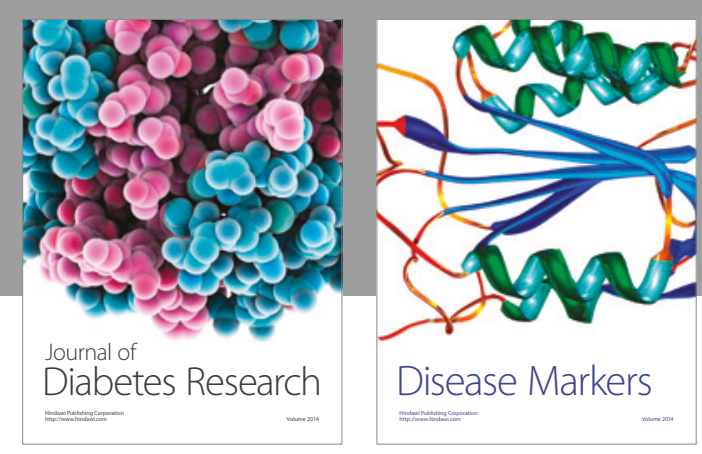

Disease Markers
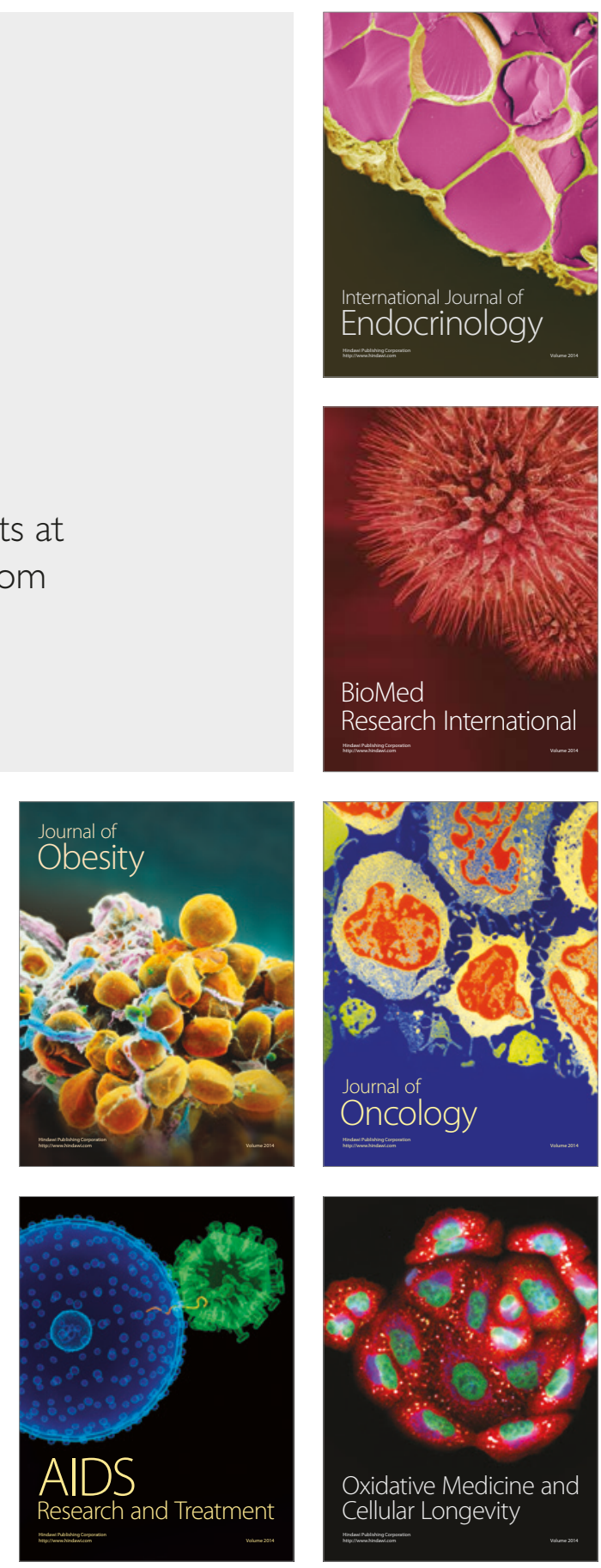